\title{
Femtosecond Laser Peening of Stainless Steel
}

\author{
Hitoshi Nakano $^{* 1}$, Sho Miyauti ${ }^{* 1}$, Nobuyuki Butani ${ }^{* 1}$, Toshiya Shibayanagi ${ }^{* 2}$, Masahiro Tsukamoto ${ }^{* 2}$, and Nobuyuki Abe ${ }^{* 2}$ \\ ${ }^{* 1}$ School of Science and Engineering, Kinki University, \\ 3-4-1 Kowakae, Higashi-osaka, Osaka 577-8502, Japan \\ E-mail: hitoshi@ele.kindai.ac.jp \\ *2 Joining and Welding Research Institute, Osaka University \\ 11-1 Mihoga-oka, Ibaraki, Osaka 567-0047 Japan
}

\begin{abstract}
We demonstrate the femtosecond laser peening, which has not been reported thus far, of stainless steel. The test sample used in the present study is commercial SUS304 stainless steel. The sample is investigated under femtosecond laser-shock loading in a plasma confined by water at the highest intensity of $56 \mathrm{TW} / \mathrm{cm}^{2}$. The Vickers microhardness test is used to probe the residual stress and strain hardening caused by laser peening. The hardness of laser-peened SUS304 increases with an increase in the laser intensity and number of laser shots irradiated per unit area. A femtosecond laser has the potential to improve the mechanical performance of stainless steel under extremely low energy irradiation of the order of several hundreds of microjoules.

DOI: $10.2961 / \mathrm{jlmn} .2009 .01 .0007$
\end{abstract}

Keywords: femtosecond laser, laser peening, laser hardening, stainless steel, SUS304

\section{Introduction}

Laser peening is a surface treatment technique that improves the mechanical performance of metals. For instance, it can be used for resistance to crack initiation, extended fatigue life, and enhanced fatigue strength [1-3]. These effects are imparted by shock waves resulting from the expansion of a high-pressure plasma caused by an intense pulsed laser. Most studies on laser peening have used nanosecond pulsed lasers [1-3]. We have studied microscale laser peening using a femtosecond laser.

A large number of studies have shown that a femtosecond laser is a good tool for precision material processing, such as precision drilling, cutting, and grooving in metals. The femtosecond laser beam does not interact with a plasma because of its ultrashort pulse duration, which allows the deposition of the complete energy on target materials without plasma absorption [4]. At laser intensities exceeding $10^{10} \mathrm{~W} / \mathrm{cm}^{2}$, a shock wave is generated due to the ignition and explosive expansion of the plasma. A highpressure plasma is easily obtained by femtosecond laser irradiation at a low energy fluence. Moreover, a femtosecond laser can be used to treat materials at a low energy fluence with high repetition rate [5]. A femtosecond laser would be a promising tool for effective laser peening.

We report in this paper the results obtained in femtosecond laser peening of stainless steel, which has never been reported thus far. The Vickers microhardness test is used to probe the strain hardening caused by laser peening. The dependence of hardness on laser parameters is also examined.

\section{Experimental}

A femtosecond laser system (IFRIT, Cyber Laser) consisting of a fiber laser oscillator and Ti:sapphire amplifier is used in the experiments. The laser beam is plane polarized after passing through a polarizer in the laser system. The pulse duration is $191 \mathrm{fs}$ at a nominal wavelength of $800 \mathrm{~nm}$,

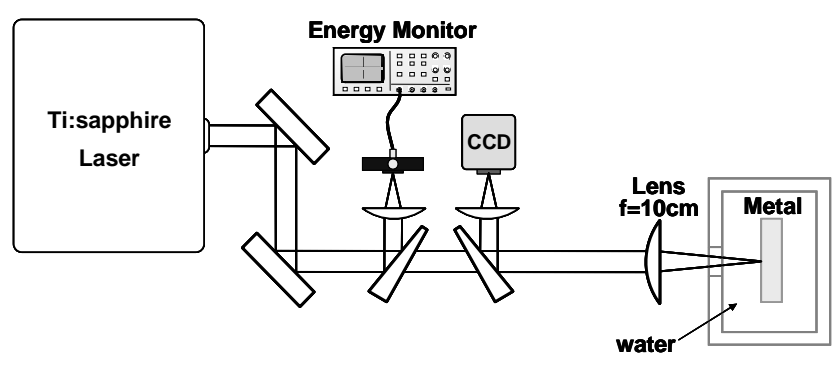

Fig. 1 Schematic illustration of femtosecond laser peening.

which is estimated using a back-ground free second order autocorrelator.

We have adopted the laser peening technique developed by Y. Sano et al. [3, 6], which can be used to introduce compressive residual stress in metals without a protective coating on target materials. This technique, additionally, can drastically reduce the laser energy required for peening by increasing the number of laser shots irradiated per unit area.

Figure 1 shows the experimental arrangement for the femtosecond laser peening of stainless steel. Austenitic stainless steel SUS304 with dimensions $2 \mathrm{~cm} \times 2 \mathrm{~cm} \times 0.5$ cm was used as the test samples. The sample was electropolished and annealed perfectly (three hour treatment at $1100^{\circ} \mathrm{C}$ ) to remove the residual stress before laser irradiation.

The laser beam after passing through two beam splitters is focused on the sample by using a lens having a focal length of $10 \mathrm{~cm}$. The sample is supported by a holder and immersed in distilled water. The position of the sample can be controlled using precision XYZ stages connected to a computer. The energy monitoring system and CCD camera shown in Fig. 1 can be used to measure the energy and laser beam profile on the sample. The focal spot is elliptical and its estimated dimensions are $40 \mu \mathrm{m} \times 80 \mu \mathrm{m}$. The av- 


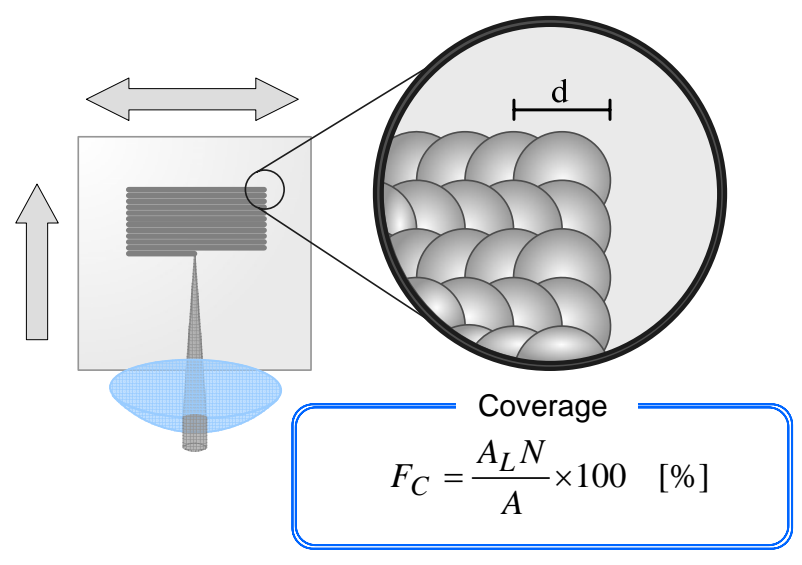

Fig. 2 Scheme of laser irradiation on a sample.

erage laser fluence is varied from 2.3 to $10.7 \mathrm{~J} / \mathrm{cm}^{2}$, and the highest laser intensity in the present experiments is estimated to be $56 \mathrm{TW} / \mathrm{cm}^{2}$. In addition, coverage $F_{C}$ is also adopted as the laser irradiation parameter, defined as,

$$
F_{C}=\frac{A_{L} N}{A} \times 100 \quad[\%],
$$

where $A_{L}$ and $A$ indicate the area of the laser focal spot and laser irradiated region, respectively, and $N$ is the number of laser shots. Figure 2 shows the schematic of the laser irradiation of the sample. In all experiments, $A$ is fixed to be $0.5 \mathrm{~cm} \times 0.5 \mathrm{~cm}$ by controlling the position of the $\mathrm{XYZ}$ stages. In order to achieve a reasonable processing time, the repetition rate of the laser pulse is adjusted to be 100 $\mathrm{Hz}$.

The Vickers microhardness test was used to probe the strain hardening caused by laser peening. The hardness of the surface and side surface was measured by using a load of $0.1 \mathrm{~N}$ for $30 \mathrm{~s}$. To suppress the strain hardening induced by all other effects except laser peening, we did not apply any mechanical force on the sample after laser irradiation. Microhardness profiles were obtained for various laser parameters.

\section{Results and discussions}

The sample after femtosecond laser peening is shown in Fig. 3. The color change of the sample surface might be caused by the reaction with nascent oxygen from water decomposed by the active plasma and intense laser pulse. The laser is incident from the bottom part of the sample, as shown in Fig. 3. The laser-generated shock wave affects both the surface and side surface during its propagation. Therefore for measurements of hardness profiles, no mechanical works to create the cross section is required. Before laser peening, both the surface and side surface hardness of the sample were approximately $200 \mathrm{Hv}$.

Figure 4(a) shows the Vickers microhardness of the sample as a function of depth with the laser fluences of 2.3, $5.0,8.0$, and $10.7 \mathrm{~J} / \mathrm{cm}^{2}$. The pulse duration and coverage are fixed to be 191 fs and $2000 \%$, respectively. The individual hardness is determined by the average of two indentations at the same depth, relative to the surface. The pro files show an increase in hardness near the surface of the

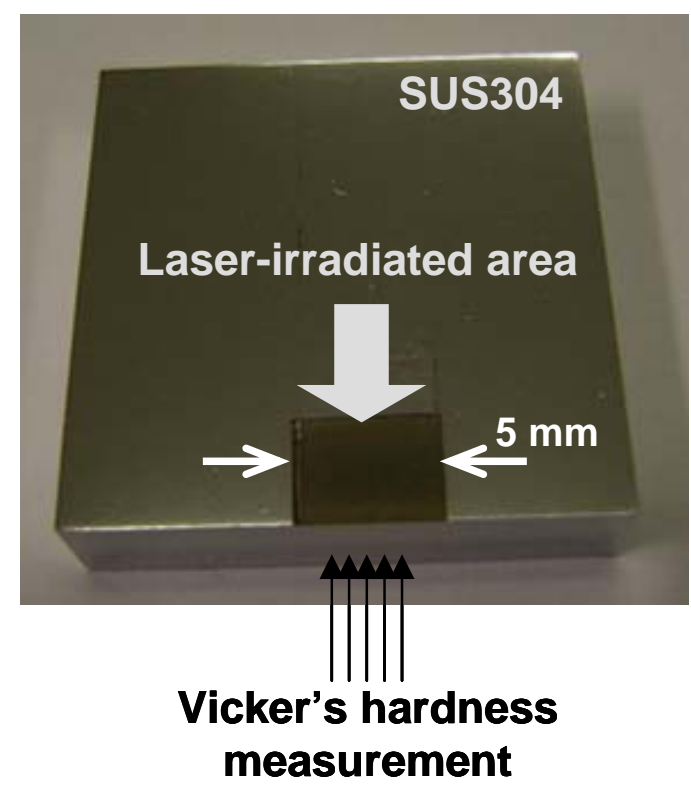

Fig. 3 SUS304 sample after femtosecond laser peening.

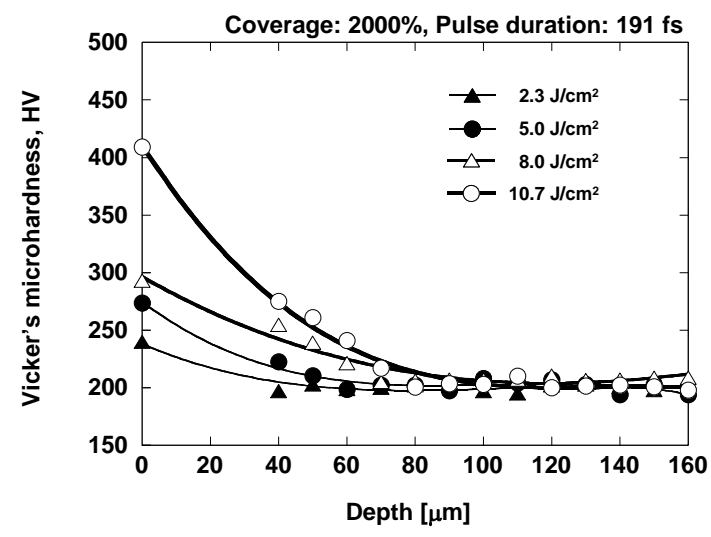

(a) Vickers hardness distributions as a function of depth.

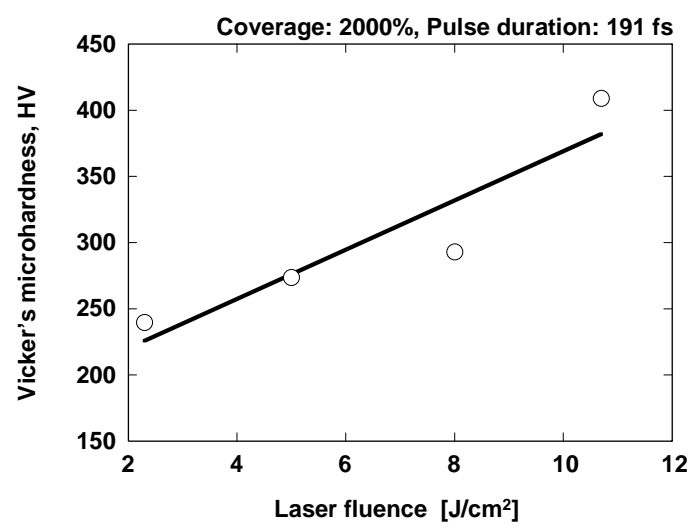

(b) Surface hardness as a function of laser fluence.

Fig. 4 Vickers hardness distribution of laser peened SUS304 various laser fluences. 


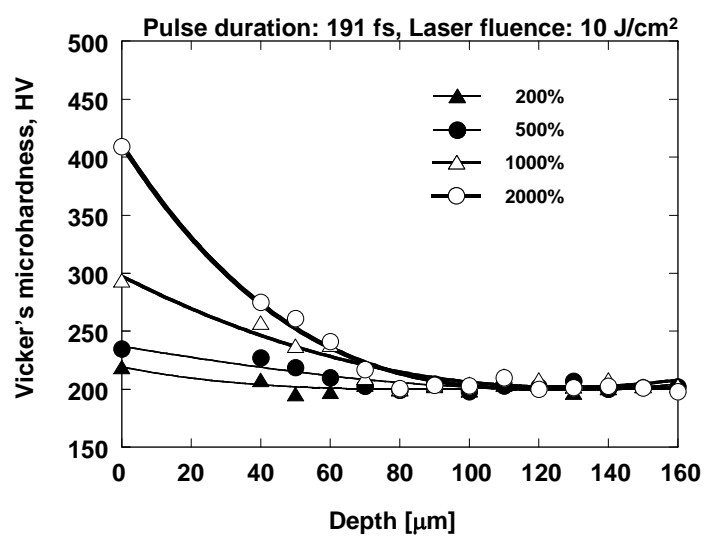

(a) Vickers hardness distributions as a function of depth.

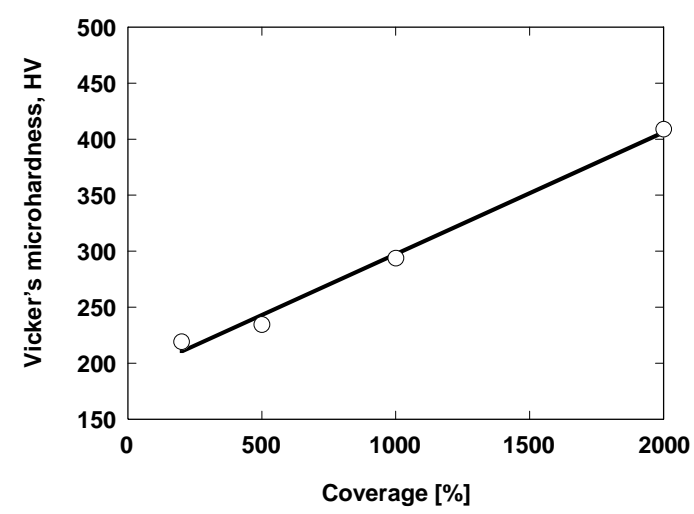

(b) Surface hardness as a function of coverage.

Fig. 5 Vickers hardness distribution of laser peened SUS304 various coverages.

laser-peened sample. The hardened layers are approximately $80 \mu \mathrm{m}$ in all experiments, which is almost same as the diameter of the spot of the focused laser beam. Increasing the laser energy does not lead to the expansion of the hardened layer; hence, the shock-affected region is determined by the spot size of the laser beam. The relation between the hardness of the surface and the laser fluence is shown in Fig. 4(b). Figure 4(b) is based on the data shown in Fig. 4(a). The hardness increase approximately linearly with increasing energy fluence. In general, the strain hardening is produced due to the plastic deformation induced by the laser-generated shock wave. The plastic deformation should increase with the increasing laser energy because shock loading is a function of the laser energy incident on the sample.

Figure 5(a) and (b) show hardness as a function of depth for various coverages, and the relation between the surface hardness and the coverage, respectively. The pulse duration and energy fluence are fixed at 191 fs and 10 $\mathrm{J} / \mathrm{cm}^{2}$, respectively. The hardness is simply proportional to the coverage. The increase in the hardness is attributed to the superposition of the laser beams shots.
We have demonstrated that the strain hardening in stainless steel caused by femtosecond laser peening. Moreover, the plastic deformation caused by the shock loading can result in residual compressive stresses [7]. Therefore, compressive stress must be introduced in stainless steel; the magnitude of this stress has not been measured. The highest hardness obtained is $409 \mathrm{Hv}$ for $10.7 \mathrm{~J} / \mathrm{cm}^{2}$ laser fluence and $2000 \%$ coverage. The hardness of the laser-peened sample is twice that of the untreated sample. This is similar to the data obtained by the laser peening with a nanosecond pulsed laser [8]. The femtosecond laser-generated shock wave in metal is characterized only by the interaction of metals with lasers. The laser does not interact with plasma since the plasma generation takes place after the termination of the laser pulse. Therefore, the shock loading time in femtosecond laser peening must be shorter than that in nanosecond laser peening [9]. However, from the hardness measurements it has been found that the amount of plastic deformation is almost the same for femtosecond and nanosecond laser peening. Further studies are necessary to investigate the residual stress in femtosecond laser-irradiated metals and their microstructure. These studies would reveal the difference between femtosecond laser peening and nanosecond laser peening.

The highest energy fluence, i.e, $10.7 \mathrm{~J} / \mathrm{cm}^{2}$, in the present experiments corresponds to the laser output energy of $300 \mu \mathrm{J}$. This energy is extremely small as compared to the energy required for nanosecond laser peening. A femtosecond laser has the potential to improve the mechanical performance of stainless steel under extremely low energy irradiation and would be a promising tool for effective laser peening.

\section{Conclusion}

We have studied the strain hardening of stainless steel caused by femtosecond laser peening. The hardness of the surface of a sample increases approximately linearly with an increase in the energy fluence and number of laser shots irradiated per unit area. The hardened layer is not related to the laser energy and coverage and is determined by the spot size of the laser beam. Additional studies that investigate the residual stress in femtosecond laser-irradiated metals and their microstructure are necessary to establish the advantages of femtosecond laser peening.

\section{Acknowledgments}

We are grateful to Miho Tsuyama for her technical assistance. This study was supported in part by Consortium R\&D projects for regional revitalization of Ministry of Economy Trade and Industry of Japanese Government.

\section{References}

[1] K. Ding and L. Ye: "Laser shock peening” (CRC press WP, 2006) Chapters 1 and 2. (Books)

[2] P. Peyre, L. Berthe, X. Scherpereel, and R. Fabbro: J. Mater. Sci., 33, (1998) 1421. (Journals)

[3] Y. Sano, M. Obata, T. Kubo, N. Mukai, M. Yoda, K. Masaki, and Y. Ochi: Mater. Sci. Eng. A, 417, (2006) 334. (Journals)

[4] B. C. Stuart, M. D. Feit, S. Herman, A. M. Rubenchik, B. W. Shore, and M. D. Perry: Phys. Rev. B, 53, (1996) 1749. (Journals) 
[5] R. Le Harzic, D. Breitling, S. Sommer, C. Fohl, K. Konig, F. Dausinger, E. Audouard: Appl. Phys. A, 81, (2005) 1121. (Journals)

[6] Y. Sano, K. Akita, K. Masaki, Y. Ochi, I. Altenberger, and B. Scholtes: J. Laser Micro/Nanoeng., 1, (2006) 161. (Journals)

[7] C. S. Montross, T. Wei, L. Ye, G. Clark and Y. W. Mai: Int. J. Fatigue, 24, (2002) 1021. (Journals)
[8] B. S. Yilbas, S. Z. Shuja, A. Arif, M. A. Gondal: J. Mater. Proc. Tech., 135, (2003) 6. (Journals)

[9] T. Sano, H. Mori, E. Ohmura, and I. Miyamoto, Appl. Phys. Lett. 83, (2003) 3498. (Journals), T. Sano, H. Moria, O. Sakata, E. Ohmura, I. Miyamoto, A. Hirose, and K. F. Kobayashi: Appl. Sur. Sci., 247, (2005) 571. (Journals)

(Received: June 16, 2008, Accepted: February 25, 2009) 